\title{
Pedagogia Oriental: corpo e educação
}

\section{Resumo}

O artigo compara a educação oriental com certas práticas do Oriente, ignoradas por nossa pedagogia. O Ocidente, sobretudo na época moderna, tende a um fragmentarismo, a uma cisão espírito/corpo, que remete a um desmedido afã de clareza no pensamento. E a grande ruptura que o moderno pensamento ocidental instituiu deu-se precisamente em torno à concepção de corpo. Já o Oriente, que "pensa" com o corpo, valoriza os ritos e as cerimônias.

\section{Abstract}

The article compares Western and Eastern educations and their practices. The Western world, mainly in modern times, splits mind and body and looks for exactness in thinking. Eastern pedagogy proposes "thinking" with the body, and so the importance of ceremonies.

Palavras Chave: Corpo e educação. Orientes e Ocidente. Cerimônias

Keywords: Body and Education. East and West. Ceremonies.

\section{Atualidade do Oriente}

Atualidade, nem sempre significa aquilo que realmente está acontecendo hoje em dia: como são atuais a violência urbana, a comunicação virtual, os enormes problemas de trânsito em São Paulo etc.
Nesse sentido, está a palavra inglesa actual, verdadeira casca de banana para os redatores de legendas, que, muitas vezes a traduzem erradamente por atual. Nesse viés do actual, actuality aponta para a realidade mais do que para "atualidade" (se bem que a realidade costuma dar-se hoje, contemporaneamente...).

Mas, aqui, estamos preocupados com outra "atualidade": a da oportunidade, conveniência, ou mesmo necessidade; como quando dizemos: nada mais atual para o Brasil do que um projeto sério de erradicação da corrupção.

É nesse sentido que falaremos da atualidade do Oriente (ou dos Orientes...) e de certas práticas da educação oriental, ignoradas (ou esquecidas, ou menosprezadas...) pela pedagogia ocidental.

\subsection{Cerimônias e ritos. O Oriente}

Cerimônias como a do Chá, que condensa em si toda uma cultura milenar e que só pode ser compreendida nessa totalidade do complexo alma-corpo; do corpo que é algo mais do que matéria; do corpo entendido como $M i$, na tradição japonesa. Por isso que, advirtase desde já, estão fadadas ao fracasso as tentativas de "importar" os "passos" da Cerimônia do Chá (como erradamente insiste em fazer a pedagogia americana), sem atentar para essa totalidade, que aponta para o espírito... É como querer ensinar, de modo meramente operacional, uma sueca a ser passista de escola de samba.

Em parceria com Jean Lauand - a quem, aliás, devo a ideia acima da atualidade de falta,

\footnotetext{
1 Chie Hirose - Doutora pela Faculdade de Educação da Universidade de São Paulo. Professora das Faculdades
} Integradas "Campos Salles”. Professora da rede municipal de São Paulo. E-mail: hirosec@hotmail.com 
de oportunidade - escrevemos um estudo intitulado "Fingir para Germinar: Educação e Antropologia", em duas partes: a primeira de Lauand; a segunda, de minha autoria.

A ideia básica para este estudo procede da parte I, de Lauand ${ }^{3}$.

Desde Platão, tornou-se evidente o caráter problemático do educar para a virtude; o que, evidentemente, transcende o âmbito meramente intelectual e envolve o homem como um todo: alguém pode conhecer profundamente as teorias morais, as classificações das virtudes, as doutrinas religiosas mais santas... e ser pessoalmente um canalha. Não que não seja importante - e mesmo uma valiosa ajuda - o estudo dos clássicos da ética, mas sempre haverá algo mais do que estudo, quando se trata de aperfeiçoamento moral.

Neste ponto, tipicamente falando, os Orientes levam uma vantagem sobre nós: enquanto o Ocidente aposta na formação intelectual; os Orientes, independentemente de teorias que as legitimem, tendem a práticas que consideram o homem como um todo: em sua unidade espírito-corpo, ao menos em muitas de suas propostas pedagógicas, que partem precisamente de uma ação corporal, exterior, para atingir um efeito espiritual, interior.

É o "pensar com o corpo", típico do Oriente e - em algumas instâncias - também da tradição ocidental.

Por mais acentuado que seja o racional nos gregos, originariamente foi temperado pela aceitação do mistério (baste recordar o discurso de Diotima no Banquete de Platão) e da comezinha realidade quotidiana, como base de todo o pensamento. Assim, não é de estranhar que praticamente a mesma cena se encontre no grande Heráclito e na tradição budista oriental.

O Mercador de Óleo ${ }^{4}$

Um dia, quando o Mestre Ch'an Chao-chou estava a caminho para o Distrito T'ung-cheng, ele encontrou o Mestre Ch'an Ta-t'ung de T'ou-tzü Shan e perguntou: "É você que é o Mestre de T'ou-tzü Shan?".

Ta-t'ung, acenando com sua mão, apregoava: "Sal, chá e óleo. Por favor, comprem!"

Chao-chou, ignorando-o, rapidamente continuou seu caminho para o templo. O Mestre Ta-t'ung seguiu atrás e chegou ao templo com uma garrafa de óleo na mão. Chao-chou disse a ele desdenhosamente: "Eu tenho ouvido falar do nome do grande Mestre Ta-t'ung de T'ou-tzü Shan por um longo tempo. Contudo, eu somente vejo um mercador de óleo".

Ta-t'ung contestou: "Eu também tenho ouvido falar que Chao-chou é um mestre Ch'an, mas de fato ele não difere em nada de uma pessoa comum. Você somente vê o mercador de óleo e não vê o verdadeiro T'ou-tzü".

Chao-chou perguntou: "Por que você diz que eu sou uma pessoa comum? O que é T'ou-tzü?".

O Mestre Ta-t'ung levantou a garrafa de óleo e gritou: "Óleo! Óleo!"

O que é "T'ou-tzü?", perguntou Chao-chou, para quem a única resposta foi "Óleo! Óleo!". Arroz, sal, chá e óleo — os alimentos básicos da vida chinesa - tal é o ensinamento do Mestre T'outzü.

Tempos depois, antes de morrer, o mestre Tat'ung disse que voltaria se a stupa estivesse vermelha.

Cem anos depois, quando os discípulos consertavam a stupa, encontraram sharira ${ }^{5}$ vermelha.

Nesse tempo, veio morar no templo o mestre Yi Tching. Todos diziam que ele era a reencarnação do Mestre Ta-t'ung.

O mestre Yi Tching escreveu um poema na stupa:

As nuvens jamais podem ser aprisionadas

Grandes Montanhas Verdes não podem ser cobertas

2. Revista Internacional d'Humanitats No. 20, 2010 Disponível em: <http://www.hottopos.com/rih20/index.htm> Acesso em: 01 jan. 2011.

3. Lauand, Jean. Disponível em: $<$ http://www.hottopos.com/rih20/jean.pdf $>$ Acesso em: 01 jan. 2011.

4. Hsing Yün Contos Ch'an vol. 1 São Paulo, Shakti, 2000, pág.50-51

5. Relíquias do Buda Shakyamuni ou de outro Bodhisattva, comumente veneradas e preservadas em stupas. 
Nas noites frias a luz do luar circunda a stupa

$\mathrm{Na}$ profunda noite de outono ouve-se apenas o sussurro dos pinheiros

Quem é T'ou-tzü?

É um mestre cujo ensinamento é tão próximo de nós como o sal, o arroz, chá e o óleo, indispensáveis à vida cotidiana.

Como dizíamos, episódio semelhante é protagonizado por Heráclito de Éfeso, tal como no-lo relata Aristóteles 6 :

Diz-se que Heráclito assim teria respondido aos estranhos vindos na intenção de observá-lo. Ao chegarem, viram-no aquecendo-se junto ao forno. Ali permaneceram, de pé (impressionados sobretudo porque) ele os encorajou (eles ainda hesitantes) a entrar, pronunciando as seguintes palavras: "Mesmo aqui os deuses também estão presentes"7

Também aqui o sábio não divaga por regiões etéreas, desvendando os arcanos dos deuses, mas encontra-se prosaicamente aquecendo-se junto ao fogão. Heidegger comenta:

Mesmo aqui, junto ao forno, mesmo neste lugar cotidiano e comum onde cada coisa e situação, cada ato e pensamento se oferecem de maneira confiante, familiar e ordinária, "mesmo aqui", nesta dimensão do ordinário, os deuses também estão presentes. A essência dos deuses, tal como apareceu para os gregos, é precisamente esse aparecimento, entendido como um olhar a tal ponto compenetrado no ordinário que, atravessando-o e perpassando-o, é o próprio extraordinário o que se expõe na dimensão do ordinário $^{8} .(\ldots)$
Quando o pensador diz "Mesmo aqui", junto ao forno, vigora o extraordinário, quer dizer na verdade: só aqui há vigência dos deuses. Onde realmente? No inaparente do cotidiano ${ }^{9}$.

Voltando a "Fingir para Germinar...", Lauand começa explicando que o Ocidente, sobretudo na época moderna, tende a um fragmentarismo, a uma cisão espírito/corpo, que remete a um desmedido afã de clareza no pensamento. E que a grande ruptura que o moderno pensamento ocidental instituiu deu-se precisamente em torno à concepção de corpo.

Dessa convicção, e continuamos seguindo o estudo citado de Lauand, brota a pedagogia do "fingir" no sentido de que a repetição - ou se quisermos seguir a tradição confuciana: o rito gera a atitude moral que se pretende adquirir. $\mathrm{O}$ "fingir" material, do corpo, induz a virtude na alma. Os exemplos apresentados desse "fingir" são de Guimarães Rosa, Shakespeare e Pascal.

A fórmula mais enxuta nos vem de uma sentença de João Guimarães Rosa: "Tudo se finge primeiro; germina autêntico é depois". ${ }^{10}$ Lauand comenta:

Um homem que reconheça um seu defeito moral, digamos a ingratidão, e queira adquirir a virtude correspondente, como deve proceder? Fingindo. Quer dizer, começa-se por assumir as formas externas, verbais da gratidão (que não se sente): "fingir" reconhecer o caráter indevido do favor recebido, "fingir" louvar o benfeitor, "fingir" sentir-se na obrigação de retribuir etc. E, um belo dia, germina autêntico aquilo que se fingia...

\footnotetext{
${ }^{6}$ De part. anim., A5 645 a 17 e ss.

${ }^{7}$ apud Heidegger, M. Heráclito, Rio de Janeiro, Relume Dumará, pág. 22.

${ }^{8}$ Heidegger, M. Heráclito, Rio de Janeiro, Relume Dumará, pág. 23-24.

${ }^{9}$ Heidegger, M. Heráclito, Rio de Janeiro, Relume Dumará, pág. 24. E Heidegger prossegue: "Não é preciso evitar o conhecido e o ordinário e perseguir o extravagante, o excitante e o estimulante na esperança ilusória de, assim, encontrar o extraordinário. Vocês devem simplesmente permanecer em seu cotidiano e ordinário, como eu aqui, que me abrigo e aqueço junto ao forno. Não será isso que faço, e esse lugar em que me aconchego, já suficientemente rico em sinais? O forno presenteia o pão. Como pode o homem viver sem a dádiva do pão? Essa dádiva do forno é o sinal indicador do que são os theoí, os deuses. São os daíontes, os que se oferecem como extraordinário na intimidade do ordinário." Etc.
}

10 "Sobre a escova e a dúvida" in Tutaméia. Rio de Janeiro: Nova Fronteira. 1985, pág. 166. 
E o "fingir" é também preconizado por Shakespeare: "Assume a virtue, if you have it not", diz Hamlet (III, 4) ${ }^{11}$.

Também Pascal situa-se na mesma direção. Em Pensées \#25012:

É necessário que o exterior se una ao interior, isto é, pôr-se de joelhos, rezar com os lábios, etc., a fim de que o homem orgulhoso, que não quis se submeter a Deus, seja submetido à criatura. Esperar socorro desse exterior é ser supersticioso; não querer ajuntá-lo ao interior é ser soberbo.

Apesar desses tão importantes pensadores, no Ocidente ainda predomina uma atitude racionalista, que exclui o corpo - e, portanto, os ritos - da educação. Se no Ocidente restam apenas resquícios da educação por ritos, como no caso da liturgia católica (também ela hoje em processo de desritualização), as propostas orientais são mais ligadas $a \operatorname{ritos}^{13} \mathrm{e} a o s$ ritos.

\section{Ao redor do fogo.}

Como dizíamos, a educação oriental aposta em ritos e ações corporais. É bem o caso da Cerimônia do Chá, da qual destacaremos um aspecto: o fogo.

A Cerimônia do Chá, em sua aparente simplicidade, induz pelo corpo o espírito em mil instâncias materiais: da porta de entrada ao modo de servir a infusão; da decoração à postura dos convivas. Não caberia aqui a descrição e discussão desses passos, objeto de meu livro Pesquisa em Cultura e Educação Uma investigação sobre a Cerimônia do Chá (São Paulo: Cemoroc-Feusp, 2011).

Muito mais que o chá, interessa-nos as possibilidades de transcendência oportunizadas pela Cerimônia.

A Cerimônia do Chá ganha sua estrutura definitiva com Sen-no-Rikyu (1522-1591) no período Momoyama (séc. XVI), o mais faustoso da história do Japão. Rikyu, homem de grande poder, conselheiro predileto do daimyo Hideyoshi, criou no Japão esplendoroso da época Momoyama um novo conceito de beleza, voltado para o simples, o despojado, o essencial, estilo que se perpetuou até nossos dias.

Rikyu, além de estabelecer as regras definitivas da Cerimônia, criou o modelo da chashitsu, ou Cabana de Chá, e de seu jardim. Ligado à filosofia Zen - ele próprio era monge zen -, imbuiu do espírito wabi (desprendimento, simplicidade, eliminação do supérfluo) tudo o que se refere à Cerimônia: local que tem a simplicidade de uma cabana de camponeses, com seu telhado rústico e teto de bambu ou caniço, janelas de treliça e paredes toscas; o jardim roji, que lembra uma paisagem da montanha e induz à meditação; a decoração sóbria etc.

\footnotetext{
${ }^{11}$ Assume a virtue, if you have it not. That monster, custom, who all sense doth eat. Of habits devil, is angel yet in this, that to the use of actions fair and good He likewise gives a frock or livery, that aptly is put on. Refrain to-night, and that shall lend a kind of easiness to the next abstinence: the next more easy. For use almost can change the stamp of nature. And either. the devil, or throw him out with wondrous potency.

12 Il faut que l'extérieur soit joint a l'intérieur pour obtenir de Dieu; c'est-à-dire que l'on se mette à genoux, prier des lèvres, etc. afin que l'homme orgueilleux, qui n'a voulu se soumettre à Dieu, soit maintenant soumis à la créature. Attendre de cet extérieur le secours est être superstitieux, ne vouloir pas le joindre à l'intérieur est être superbe.

13 Aqui recorro uma vez mais às aulas de Jean Lauand, que nos narrava uma antiga lenda da comunidade judaica polonesa: para afastar os perigos, a cada trinta anos, o rabino conduzia a comunidade a uma determinada clareira na floresta, recitava certas orações e fazia gestos rituais e isso mantinha a comunidade segura. Tendo morrido o velho rabino, ao chegar o ano certo alguém lembrou de que deveriam realizar o rito. O novo rabino não dominava tão bem o rito, mas com ajuda dos mais velhos, acabaram achando a clareira, e (com muita dificuldade) lembraram-se das orações e gestos e a comunidade respirou aliviada. Trinta anos depois, outro rabino. Mas desta vez nem havia clareira e ninguém se lembrava das etapas rituais. Os membros da comunidade começavam a ficar aflitos e temerosos, porque não poderiam contar com a cerimônia de proteção, quando o rabino sabiamente os tranquilizou: "Não se preocupem, só pelo fato de lembrarmos que há um rito a comunidade está muito bem protegida...". Há versão recente dessa lenda em JeanClaude Carrière, Le Cercle des menteurs, contes philosophiques du monde entier; Paris, Plon, 1998. pág. 430-431.
} 
Segundo Rikyu, o "Caminho do Chá" deve ter na Harmonia ( $W a)$, no Respeito $(K e i)$, na Pureza ( $\mathrm{Sei})$ e na Tranquilidade (Jaku) os seus princípios basilares. O "homem de chá" (chajin) deve saber criar na sala de chá, por meio do rígido ritual e de sua participação total, a atmosfera adequada para que esses princípios sejam sentidos e vividos intensamente, por um momento, único e irrepetível, por todas as pessoas participantes da Cerimônia.

Dentre as centenas de ações corporais que induzem aos valores pretendidos pela Cerimônia, limitar-nos-emos ao fogo, ao fogareiro (ro ou furo $)^{14}$, prevista por Rikyu.

A antropologia nos revela que para várias culturas, o fogo é representado como elemento de purificação, mudança, transformação. Cerimônias e ritos são realizados, invocando na chama a luz do sagrado.

Muitos povos nativos acreditam que sentados ao redor de uma fogueira, os participantes ativam a intuição e a emoção e eles podem se conectar com suas outras dimensões: espirituais, temporais, sobrenaturais, transcedentais. Neste lugar são trocados conselhos e ensinamentos e tomadas decisões relacionadas à comunidade, porque o fogo é utilizado para ativar a luz da Sabedoria.

Por exemplo, os Mbyá-Guarani:

É ao redor da fogueira que ocorrem as principais atividades femininas e onde se reúne a família para fazer as refeições e recepcionar as visitas. Logo nas primeiras horas da manhã os MbyáGuarani se reúnem em torno da fogueira para tomar chimarrão e conversar sobre o que sonharam durante a noite. Todos conversam enquanto as mulheres preparam, ali mesmo, a primeira refeição do dia. Sempre que possível este "café-da-manhã" é tomado em grandes grupos: pessoas de várias casas, vizinhos e/ou parentes se reúnem em uma única casa. Ocorre um revezamento das casas que oferecem o "café". Se para nós ocidentais é bonito uma mesa cheia de gente, para os Mbyá-Guarani, que não se valem de mesas, é bonito ter muitas pessoas reunidas em torno da fogueira. ${ }^{15}$

O que seria o "fogo" para a Cerimônia do Chá? Desde há séculos, a sociedade japonesa tem feito do irori, fogareiro embutido ao nível do solo, o ponto centralizador, o lugar onde as pessoas da casa se reunem. ${ }^{16}$

O Chanoyu estipula o fogo como o ponto central para reunir as pessoas e aí nasce o interrelacionamento entre os presentes. Originalmente, o ro (fogareiro enbutido no nível do tatami) que existia em casas de agricultores, diz-se que foi trazido ao recinto do Chá através de Jô-ô e Rikyu. Ro, literalmente, é o "foco" ou ponto de queima" (em japonês ambas palavras lêem-se "shôten" mas de ideogramas diferentes) e sem o fogo do carvão, de cor de rubi, como o centro das coisas, não terá sentido a realização do chakai. ${ }^{17}$

O Chanoyu que é também chamado de cultura da hospitalidade revela-nos o modo como é representado o fogo na antiga cultura japonesa. O acolhimento, em princípio, significa receber e acolher a Deus e é representado pelo lugar do fogareiro. Assim, Deus está no iroro. Até tal ponto, que Rikyu

\footnotetext{
${ }^{14}$ Ro: pequeno fogareiro quadrado, com cerca de $0,30 \mathrm{~m}$ de lado, enterrado no solo, no nível dos tatame, e utilizado na cerimonia de chá feita nos Chashitsu. Frédéric, Louis. O Japão - dicionário e civilização, São Paulo: Ed. Globo, 2008, pág. 972. Furo: fogareiro portátil.
}

15 MÁRTIN, César Tempass. "O belo discreto: a estética alimentar mbyá-guarani” Espaço Ameríndio, Porto Alegre, v. 1, n. 1, pág. 170-194, jul./dez. 2007. Disponível em: <http://seer.ufrgs.br/index.php/EspacoAmerindio/article/viewFile/ 2567/1568>. Acesso em: 01 nov. 2007.

16 irori: fogareiro aberto, geralmente quadrado, colocado entre a cozinha e a peça principal de uma casa, principalmente na zona rual, em torno do qual os membros da família se reuniam durante as noites longas de inverno. Cada um tinha seu lugar reservado. O irori, fixo, servia ao mesmo tempo como aquecedor e fonte de luz. Foi progressivamente substituído pelos fogareiros portáteis, os hibachi, no século XIX. Frédéric, Louis. O Japão - dicionário e civilização, São Paulo: Editora Globo, 2008, pág. 505.

17 Centro de Chado Urasenke do Brasil. Chanoyu : Arte e Filosofia São Paulo: Aliança Cultural Brasil-Japão, 1995, pág. 140 . 
suprimiu as mesas da Cerimônia e introduziu o chashitsu, consolidando a forma que se prolonga até a atualidade: ritual feito em torno do fogareiro.

O deus do fogo protege a comunidade e também é aquele que protege a nossa casa. Esse Deus despreza o kegare, que pode ser traduzido como impuro. Kegare é um conceito muito particular da antiga cultura misturada à influência do shintoísmo ${ }^{18}$; não corresponde à concepção de pecado que predomina na cultura cristã. Podemos imaginar a impureza (kegare) como a sujeira ou contaminação, que na concepção japonesa se refere ao estado de coisas em desequilibrio. Esse desequilíbrio pode ser momentâneo de movimentos. Quando existe desequilíbrio entre o céu e a terra, ocorre o terremoto; quando há perturbação no equilíbrio do corpo, ficamos doentes. Para removermos o kegare, é necessário a kiyome (purificação-harmonia). Podemos traduzir a Cerimônia de Chá exatamente como cerimônia da kiyome. ${ }^{19}$

Assim, a Cerimônia de Chá valoriza a harmonia. Harmonia entre pessoa e pessoa, objeto e objeto, entre pessoa e objeto. A harmonia é encontrada até nas cinzas depositadas no fogareiro, que cuidadosamente são arrumadas em forma de montanha. Em vez de serem ignoradas no ritual como algo já acabado, consumido pelo fogo, é incluído e apreciado como parte da beleza do ambiente. Uma bela observação:
Podemos ainda acrescentar que no Chanoyu até o modo de se desfazer das cinzas do ro e furo se resolve de forma artística. Observando bem a forma das cinzas feitas com tanto empenho espiritual, não se pode deixar de pensar na lenda da Fênix no plano terreno. O resíduo branco do carvão que parece realmente concluir a tarefa do chakai não se projeta como um resíduo ósseo, mas daí, sobretudo, faz-se sentir a sublimação do imortal pássaro. ${ }^{20}$

Acredita-se que todo procedimento que se encontra no ritual do chá é em busca destas harmonias e se prolonga para a harmonização do nosso corpo, ou seja, que o nosso coração se conecte com a mente e que o corpo atinja assim o seu equilíbrio.

É uma cerimônia que dá ênfase ao quotidiano, ao aqui e agora, aos gestos e objetos do dia a dia. Como se evidencia na passagem da descrição de uma "cerimônia" privada, oferecida por Rikyu a um colega Sokyu, mestre do chá, narrada por Burch:

\begin{abstract}
$\mathrm{O}$ anfitrião e o visitante tinham trocado algumas palavras quando ouviram a porta da cozinha se abrir. Rikyu explicou tratar-se do criado que enviara a Samegi, lugar famoso pela água, que tinha acabado de voltar. Dizendo que agora iria buscar a água, Rikyu ergueu a chaleira e foi para a cozinha. Sakyu aproximou-se do fogo e o observou, agora que a chaleira não estava ali. $\mathrm{O}$ carvão, disposto de modo a saudar a alvorada, era de uma beleza indizível. Erguendo os olhos, Sakyu notou um suprimento de carvão cuidadosamente guardado num recipiente, na prateleira. Apanhou um pouco, jogou ao fogo e limpou o braseiro com uma escova de penas. Quando o idoso anfitrião reapareceu, vindo da cozinha com a chaleira na mão, Sokyu explicou que tinha adicionado mais carvão ao fogo, pois achou que seria necessário para ferver a água fresca, embora lamentasse ter sido obrigado a desaparelhar o belo arranjo do anfitrião. Rikyu ficou profundamente emocionado e cumprimentou Sokyu, dizendo-se encantado por
\end{abstract}

\footnotetext{
${ }^{18}$ Por exemplo: kiribi: "fogo sagrado" utilizado em algumas cerimônias shintô e produzido pelo atrito de dois pedaços de madeira, geralmente de cipreste (hinoki), ou batendo pederneiras num ferro. Antigamente, acreditava-se que as faíscas produzidas pelas pederneiras purificavam a pessoa que as recebia; essa tradição ainda é seguida, às vezes, para purificar alguém que sai de uma casa e protegê-lo. Frédéric, Louis. O Japão - dicionário e civilização, São Paulo: Editora Globo, 2008, pág. 660.

${ }^{19}$ Disponível em: <http://www.omotesenke.jp/chanoyu/b_1.html>. Acesso em: 01. set. 2011

${ }^{20}$ Centro de Chado Urasenke do Brasil. Chanoyu : Arte e Filosofia São Paulo: Aliança Cultural Brasil-Japão, 1995, pág. 141 . 
receber visita tão atenciosa. Como a noite de inverno fosse longa, ainda faltava algum tempo para o raiar da aurora, Rikyu, dizendo que gostaria de servir o chá enquanto durasse o fogo, trouxe uma refeição ligeira. Enquanto comiam, sentados, o dia rompeu. ${ }^{21}$

\section{Referências Bibliográficas}

BURCH, Noël "Ozu Yasujiro" in Nagib, Lúcia e Parente, André (orgs.). Ozu: o extraordinário cineasta do cotidiano. São Paulo: Ed. Marco Zero. 1990.

CENTRO DE CHADO URASENKE DO BRASIL. Chanoyu: Arte e Filosofia. São Paulo: Aliança Cultural Brasil-Japão, 1995.

FRÉDÉRIC, Louis. O Japão - dicionário e civilização, São Paulo: Ed. Globo, 2008

HEIDEGGER, M. Heráclito, Rio de Janeiro, Relume Dumará,1998.

LAUAND, Jean. Fingir para Germinar: Educação e Antropologia. Disponível em:<http://http:// www.hottopos.com/rih20/jean.pdf> Acesso em: 01 jan. 2011.

MÁRTIN, César Tempass. O belo discreto: a estética alimentar mbyá-guarani. Espaço Ameríndio, Porto Alegre, v. 1, n. 1, pág. 170-194, jul./dez. 2007. Disponível em: <http:// seer.ufrgs.br/index.php/EspacoAmerindio/article/viewFile/2567/1568>. Acesso em: 01 nov. 2007.

REVISTA INTERNACIONAL D’HUMANITATS. No. 20, 2010 Disponível em: <http:// www.hottopos.com/rih20/index.htm> Acesso em: 01 jan. 2011.

Sobre a escova e a dúvida. In: ROSA, Guimarães. Tutaméia. Rio de Janeiro: Nova Fronteira. 1985

YÜN, Hsing. Contos Ch'an vol. 1. São Paulo, Shakti, 2000.

21. Burch, Noël " Ozu Yasujiro " in Nagib, Lúcia e Parente, André (orgs.). Ozu: o extraordinário cineasta do cotidiano. São Paulo: Ed. Marco Zero. 1990, p. 55. 